\title{
Detecting Individuals with Borderline Personality Disorder in the Community: An Ascertainment Strategy and Comparison with a Hospital Sample
}

\section{Citation}

Korfine, Lauren, and Jill M. Hooley. 2009. Detecting individuals with borderline personality disorder in the community: An ascertainment strategy and comparison with a hospital sample. Journal of Personality Disorders 23(1): 62-75.

\section{Published Version}

http://dx.doi.org/10.1521/pedi.2009.23.1.62

\section{Permanent link}

http://nrs.harvard.edu/urn-3:HUL.InstRepos:3197518

\section{Terms of Use}

This article was downloaded from Harvard University's DASH repository, and is made available under the terms and conditions applicable to Other Posted Material, as set forth at http:// nrs.harvard.edu/urn-3:HUL.InstRepos:dash.current.terms-of-use\#LAA

\section{Share Your Story}

The Harvard community has made this article openly available.

Please share how this access benefits you. Submit a story.

\section{Accessibility}




\title{
DETECTING INDIVIDUALS WITH BORDERLINE PERSONALITY DISORDER IN THE COMMUNITY: AN ASCERTAINMENT STRATEGY AND COMPARISON WITH A HOSPITAL SAMPLE
}

\author{
Lauren Korfine, PhD, and Jill M. Hooley, DPhil
}

\begin{abstract}
Most empirical research on borderline personality disorder (BPD) draws its participant pool from clinical samples. Individuals with BPD recruited from clinical settings, however, may represent a unique subset of those with the illness. The present study sought to determine (a) whether individuals with diagnosable BPD could be readily ascertained from the community and (b) how such individuals would compare to those drawn from a clinical setting on various dimensions. We found that the clinical sample showed a somewhat more severe expression of illness, a different pattern of BPD symptoms, somewhat greater Axis I comorbidity, and more medication and prior hospitalization than the community sample. On other clinical dimensions (e.g., depression, anxiety, dissociation, positive and negative affect) however, the two groups were quite similar. Results suggest that some research questions might be addressed better with participants from community samples, while others might be better suited to clinical samples.
\end{abstract}

One consequence of the polythetic nature of the DSM-IV, is the considerable heterogeneity that arises within diagnostic categories (Clark, Watson, \& Reynolds, 1995) particularly among the personality disorders (PDs; Widiger \& Frances, 1985). For example, in borderline personality disorder, the polythetic format allows for individuals to receive the same diagnosis for one of 126 different combinations of symptoms. The issue of diagnostic heterogeneity is important for PD researchers interested in detection of

From Department of Psychology, Harvard University.

This research was completed in partial fulfillment of a doctoral dissertation in psychology at Harvard University by Lauren Korfine. It was supported in part by NIMH National Research Service Award (5 F31 MH11233-02), a Sackler Fellowship in Psychobiology, and by Rand and Tally Restricted Fund Awards from the Department of Psychology, Harvard University.

We are grateful to Pamela McCarthy and Heather Weston for their assistance with data collection and management. We also thank John Clarkin and Perry Hoffman for their support of this research at the New York Hospital. We thank Drew Westen, Harold Koenigsberg, and Kenneth Silk for useful consultations.

Address correspondence to Lauren Korfine, 420 Utica Street, Ithaca, New York 14850; E-mail: LK79@cornell.edu 
etiological factors, endophenotypes (Gottesman \& Gould, 2003), as well as those concerned with treatment outcome. Are certain etiological factors relevant to one symptom or constellation of symptoms but not another (cf., Depue \& Lenzenweger, 2005)? Can endophenotypes be reliably associated with certain symptom features or profiles (e.g., Korfine \& Hooley, 2000)? Are certain constellations of symptoms more likely to respond to particular treatment strategies? And if so, what are the implications for discussions of the larger disorder as a unitary construct, bearing in mind that unitary disorders can reveal themselves through diverse symptomatology? Because large samples and statistical procedures that rely on measures of central tendencies can help to diminish the effects of symptom variations from person to person within a sample, the issue of diagnostic heterogeneity is not as important to consider for an individual study. This issue may be more salient, however, when different samples, particularly those drawn from different settings, are compared.

Experimental psychopathologists often obtain study participants from various settings (e.g., hospitals, outpatient clinics, the community, and universities). A common, but often unstated assumption is that participants who meet diagnostic criteria for a particular disorder will tend to show a similar profile of symptoms, even if they are ascertained from different settings (see also Maher, 2003). However, this may or may not be the case, particularly in the case of personality disorders.

This study sought to compare clinical and community-based samples of individuals with borderline personality disorder (BPD). Having BPD and being in a clinical setting may be associated with other third variables that are more likely to be associated with being in a clinical setting than with having BPD (e.g., help-seeking, medication, suicidality, comorbidity). For researchers interested in etiological factors or treatment outcome, those third variables could complicate the interpretation of any potential findings. Whether BPD individuals drawn from clinical settings generate a different symptom profile, show greater severity, or different patterns of comorbidity for BPD than those drawn from community settings has not yet been empirically tested. Koenigsberg (1982) compared inpatient and outpatient BPD samples and found that despite some differences in substance abuse, self-harm, and treatment history, the two samples were actually quite similar phenomenologically. The current study extends this finding by comparing a clinical and community BPD sample. In related research, Hurt, Clarkin, Frances, Abrams, and Hunt (1985), in a study of MMPI characteristics of BPD (inpatient and outpatient) versus Other PD (inpatient and outpatient) found no evidence of significant interactions between PD status and inpatient vs. outpatient status.

The primary goal of this report is to address two questions: (1) Can a sample of individuals with DSM-IV BPD be readily ascertained from a community population? and (2) if so, do clinical BPD samples and community based BPD samples differ reliably on various phenomenological dimensions? To address the first question, we report on our ascertainment strat- 
egy for assembling a sample of borderline individuals from the community. To address the second question, we will compare these two groups on BPD symptomatology, lifetime Axis I conditions, and personality and affect measures. We hypothesized that the two groups would not substantially differ phenomenologically. We did, however predict that the clinical group might show greater severity of BPD symptoms, more impulsivity and selfharm, and greater Axis I comorbidity than the community group, since these factors are all likely to increase the probability of hospital admission. We are agnostic as to the cause(s) of such differences and see any number of possibilities as being relevant here, including intrapersonal factors (neurobiological variation, trauma history) as well as psychosocial factors (e.g., differences in social support/density of the social network, e.g., Clifton, Pilkonis, \& McCarty, 2007). Finally, in this context, we note our approach to selecting BPD affected individuals from the community shares some features in common with the methodology described by Widom (1977) for the study of nonintitutionalized psychopaths.

\section{METHODS}

\section{PARTICIPANTS AND SELECTION PROCEDURES}

Study participants were selected as part of a larger study of memory functioning in BPD (Korfine, 1998; Korfine \& Hooley, 2000). Three groups of study participants were ascertained from two settings. One group was selected from a day treatment program at The New York Hospital/Cornell Medical Center. This program specializes in the treatment of BPD. The other two groups (BPD healthy controls) came from the community in and around Cambridge, Massachusetts, and were recruited through newspaper advertisements. All participants were aged 18-40 with a high school education or equivalency. Participants in the borderline groups met DSMIV (American Psychiatric Association, 1994) criteria for BPD as assessed by the International Personality Disorder Examination (IPDE; Loranger et al., 1994; Loranger, 1999), and none met criteria for schizophrenia or schizoaffective disorder. Control group participants displayed no features of BPD and had no current or lifetime Axis I condition. This study therefore employed three groups: a hospital borderline (BPD-H), community borderline (BPD-C), and community control (C) group.

\section{PRIMARY ASSESSMENT MEASURES}

The Omnibus Personality Inventory (OMNI; Loranger, 1994, 2002). Community participants were screened using the borderline items from the OMNI. This questionnaire uses a seven-point Likert-type scale to measure features of all DSM-IV Axis II personality disorders. Preliminary evidence suggests it has acceptable levels of internal consistency and criterion validity (Lenzenweger, Loranger, Korfine, \& Neff, 1997). 
International Personality Disorder Examination (IPDE; Loranger, 1999; Loranger et al., 1994). The IPDE is a structured clinical interview that systematically surveys the phenomenology and life experiences relevant to the diagnosis of all DSM-IV Axis II (and ICD-10) personality disorders. Interrater reliability of the IPDE has been shown to be generally excellent. Short-term test-retest reliability is also good. The IPDE generates few false positives and is generally regarded as a conservative diagnostic instrument. The BPD module of the IPDE interview was administered by the first author, who had received appropriate training. The intraclass correlation coefficient for IPDE dimensional BPD score was .88 between the author and one of the co-developers of the IPDE based on a randomly selected sample of 9 cases. All BPD participants in the current study met criteria for definite or probable BPD on the IPDE.

Structured Clinical Interview for DSM-III-R-Nonpatient (SCID-NP; Spitzer, Williams, Gibbon, \& First, 1990). The SCID-NP is a structured interview designed to generate diagnoses for the major Axis I syndromes in nonpatient samples. It has demonstrated good reliability and validity. The SCID was administered to all participants in the study by the first author who received appropriate training in its administration and scoring as well as supervision on all interviews.

\section{SECONDARY ASSESSMENT MEASURES}

Beck Depression Inventory (BDI; Beck, Ward, Mendelsohn, Mock, \& Erbaugh, 1961). This widely used 21 -item self-report inventory was used to measure depressive/dysphoric features in the study subjects.

Spielberger State Trait Anxiety Inventory (STAI; Spielberger, 1983). The STAI is a 40 item self-report instrument that is commonly used for the assessment of state and trait anxiety.

Shipley Institute of Living Scale (Zachary, 1991). General intelligence was measured using the Shipley Institute of Living Scale. This is a short (40 item) self-administered scale. It is comprised of two subtests-vocabulary and abstraction (pattern completion). Conversion tables are provided for WAIS-R IQ estimations. The average correlation between total Shipley score and WAIS-R full-scale IQ has been found to be $r=.74$ (Zachary, 1991).

General Behavior Inventory (GBI; Depue, Kraus, Spoont, \& Arbisi, 1989). The GBI is a 73-item self-report questionnaire that measures trait-based vulnerability to depression and mania. The GBI has excellent reliability (internal consistency $\alpha=.94$, test-retest $r=.73$ ) and validity in detection of clinically significant affective disturbance.

Dissociative Experiences Scale (DES; Bernstein \& Putnam, 1986; Carlson \& Putnam, 1993). The DES is a 28 item, widely used measure of various types of dissociative experiences. Subjects are asked to indicate the percentage of time they experience a particular dissociative experience. The DES has good test-retest reliability and has been shown to have very 
good criterion validity in detecting pathological dissociation (Bernstein \& Putnam, 1986).

Buss-Durkee Hostility-Guilt Inventory (Buss \& Durkee, 1957). The BussDurkee is a true-false questionnaire that measures various types of physical and psychological hostility. To be included in the scale, items had to have an item-total correlation of at least .40. We used the assault and irritability subscales of the questionnaire, consistent with current practice (Brown, Goodwin, Ballenger, Goyer, \& Major, 1979; Coccaro et al., 1989).

Positive and Negative Affective Schedule (PANAS; Watson, Clark, \& Tellegen, 1988). The PANAS is a 20 item rating scale designed to measure positive and negative affect. Participants rate the degree to which the item describes the way they feel or have felt (e.g., hostile, enthusiastic). In this study, subjects were instructed to complete the PANAS thinking about how they are in general to provide a more "trait-like" assessment. The PANAS has good psychometric properties, particularly for a short questionnaire.

\section{ASSESSMENT PROCEDURES}

Community Borderline Group. Borderline participants were solicited through placement of advertisements in newspapers, laundromats, libraries, grocery stores, video stores and other locations in the community. The advertisement read:

Do your relationships tend to be stormy? Do your feelings about people run "hot" and “cold?"Do your friends say you're "moody?"Are you really impulsive or spontaneous? Are you so different in different situations that you don't know what to expect of yourself?

Respondents to the advertisements received and returned a questionnaire packet via mail. This included the BPD scale of the OMNI, as well as the GBI, the DES, and the Buss-Durkee Hostility Index. Subjects that completed the screening measures received a $\$ 15.00$ honorarium.

Those subjects who self-reported five or more BPD features on the OMNI (corresponding to the DSM-IV cutoff for BPD diagnosis) were invited into the laboratory for diagnostic interviews. The IPDE was used to confirm DSM-IV PD diagnosis. In addition, participants completed a SCID interview to assess Axis I pathology and to screen for psychosis. Those participants who met criteria for definite or probable (i.e., one criterion short of threshold) BPD during the interview phase were asked to return to the laboratory for a second time. During this session, subjects completed the BDI, the STAI, the PANAS, as well as various memory tasks (see Korfine \& Hooley, 2000). Subjects that completed the interview as well as the laboratory procedures were paid at the rate of $\$ 10.00$ per hour for their participation in the study.

One hundred thirty-four individuals responded to the borderline advertisements. Of these, $110(82.1 \%)$ completed and returned the question- 
naire packet. Based on their responses to the questionnaires, 56 subjects were invited to be interviewed and 38 completed the interview phase. Of the 38 participants interviewed, 28 met criteria for inclusion in the experimental study and 23 (82\%) completed the experimental phase.

Community Control Group. A similar ascertainment strategy was used to obtain a normal control group. The advertisement indicated that study participants should have no history of treatment for a psychological or psychiatric condition and no history of drug or alcohol abuse.

Of the 88 respondents, 80 (90.1\%) completed and returned the questionnaire packet. Forty-one of those people were invited to be interviewed based on their questionnaire responses (i.e., zero BPD features on the OMNI) and 29 completed the interview phase. Twenty-one of these 29 met criteria for inclusion in the study (i.e., no BPD features and no lifetime or current Axis I pathology) and 20 (95\%) completed the experimental phase.

Hospital Borderline Group. Individuals in the day treatment program were attending the hospital 5 days per week for a half day. All day program patients (except one) had been inpatients receiving treatment for BPD at New York Hospital prior to joining the day program. Because these individuals were already pre-selected for BPD, the screening instrument (OMNI) was not administered. The IPDE, however, was used to confirm the hospital diagnosis of BPD. The interview procedures were identical to those used with the community groups. Twenty-three people completed the interview phase of the study. All 23 met definite or probable criteria for BPD on the IPDE and $22(96 \%)$ completed the experimental procedures. These subjects were also paid at the rate of $\$ 10.00$ per hour for their research participation.

\section{RESULTS}

Results will be reported for the final sample that was ascertained using the procedures outlined above. These are individuals who met full criteria for inclusion in the sample and who completed the experimental procedures of this study. ${ }^{1}$ Data for the control group will be provided for comparison to the two BPD groups only for all measures except the IPDE and SCID-NP because control participants were selected for absence of pathology indicated by these two instruments. All findings will be reported by group, i.e., hospital BPD $(n=22)$, community BPD $(n=23)$, control $(n=20)$.

\footnotetext{
1. Although discussion of the experimental findings from this study are beyond the scope of this report, we have chosen to report only on the sample that completed the experimental procedures for two reasons. (1) These participants have complete data on all measures. (2) Since we are offering these findings primarily for the purposes of describing samples that can be used for research studies, we wanted to describe the individuals who completed all phases of the study.
} 


\section{DEMOGRAPHICS}

Table 1 displays the demographic characteristics of the sample. The groups did not differ on age, $F(2,62)=.96, p=.390)$, sex, $\chi^{2}(2)=2.93, p=$ .231 , or ethnicity, $\chi^{2}(6)=3.68, p=.720$. Group differences did emerge on education, $F(2,62)=4.90, p=.011$, such that control subjects had more education than hospital BPD subjects. Another demographic variable that differed among the groups was marital status. The group by marital status chi-square with three levels of each variable was significant $\left(\chi^{2}=9.94, p=\right.$ .04). Since the two BPD groups did not differ on marital status $\left(\chi^{2}=1.83\right.$, $p=.40$ ), and few study participants were divorced or separated, the variables were collapsed in order to create a more interpretable 2 by 2 chisquare analysis with one degree of freedom. The 2 (group: BPD vs. control) by 2 (marital status: single vs. married) analysis was significant $\left(\chi^{2}=7.91\right.$, $p=.005)$. More BPD participants than controls were single $(95 \%$ vs. $70 \%$, respectively).

\section{GENERAL INTELLIGENCE}

An estimate of general intellectual functioning (WAIS-R equivalent) was calculated based on scores on the Shipley Institute of Living Scale. The BPD-C group $(M=108.87, S D=9.08)$ and the control group $(M=109.25$, $S D=8.19$ ) did not differ on the Shipley, but both attained higher scores than the BPD-H group $(M=102.67, S D=9.00$; contrast $t(61)=2.73, p=$ $.008, r=.33)$.

\begin{tabular}{|c|c|c|c|c|c|c|}
\hline \multirow[b]{2}{*}{ Characteristic } & \multicolumn{2}{|c|}{$\begin{array}{c}\text { Hospital } \\
\text { Borderline }\end{array}$} & \multicolumn{2}{|c|}{$\begin{array}{c}\text { Community } \\
\text { Borderline }\end{array}$} & \multicolumn{2}{|c|}{ Control } \\
\hline & $M$ & SD & M & SD & M & SD \\
\hline Age (years) & 30.7 & 6.2 & 28.2 & 7.2 & 28.5 & 6.3 \\
\hline \multicolumn{7}{|l|}{$\operatorname{Sex}(\%)$} \\
\hline Female & \multicolumn{2}{|c|}{90.9} & \multicolumn{2}{|c|}{78.3} & \multicolumn{2}{|c|}{70.0} \\
\hline Male & \multicolumn{2}{|c|}{9.1} & \multicolumn{2}{|c|}{21.7} & \multicolumn{2}{|c|}{30.0} \\
\hline \multicolumn{7}{|l|}{ Education (\%) } \\
\hline High School & \multicolumn{2}{|c|}{9.1} & \multicolumn{2}{|c|}{13.0} & \multicolumn{2}{|c|}{5.0} \\
\hline Some College & \multicolumn{2}{|c|}{63.6} & \multicolumn{2}{|c|}{39.1} & \multicolumn{2}{|c|}{25.0} \\
\hline College Graduate & \multicolumn{2}{|c|}{27.3} & \multicolumn{2}{|c|}{34.8} & \multicolumn{2}{|c|}{35.0} \\
\hline Postgraduate & \multicolumn{2}{|c|}{0.0} & \multicolumn{2}{|c|}{13.0} & \multicolumn{2}{|c|}{15.0} \\
\hline \multicolumn{7}{|l|}{ Marital Status (\%) } \\
\hline Single & \multicolumn{2}{|c|}{81.8} & \multicolumn{2}{|c|}{82.6} & \multicolumn{2}{|c|}{70.0} \\
\hline Married/Cohabiting & \multicolumn{2}{|c|}{0.0} & \multicolumn{2}{|c|}{8.7} & \multicolumn{2}{|c|}{30.0} \\
\hline Divorced & \multicolumn{2}{|c|}{9.1} & \multicolumn{2}{|c|}{8.7} & \multicolumn{2}{|c|}{0.0} \\
\hline \multicolumn{7}{|l|}{ Ethnicity (\%) } \\
\hline Caucasian & \multicolumn{2}{|c|}{90.1} & & & 85 & \\
\hline African-American & & & & & & \\
\hline Latino/Latina & & & & & 10 & \\
\hline Asian/Pacific Islander & & & & & & \\
\hline
\end{tabular}




\section{HOSPITALIZATION AND MEDICATION}

Of the 23 BPD-C participants, seven (30.4\%) had one or more previous inpatient psychiatric hospitalizations, compared with 21 (95.5\%) of the 22 BPD-H participants. A Mann-Whitney $U$ test was performed to compare rates of hospitalization. (A nonparametric test was used because some study participants had more hospitalizations than they were able to count.) The mean ranking of the BPD-H group $(M=30.90)$ was significantly higher than the mean ranking for the BPD-C group $(M=14.83, p<$ $.001)$, indicating that the hospital group had many more previous inpatient hospitalizations than the community group.

None of the control participants was taking psychiatric medications at the time of the study. Of the 23 BPD-C subjects, $11(47.8 \%)$ were taking at least one medication. Twenty-one (95.5\%) of the $22 \mathrm{BPD}-\mathrm{H}$ subjects were on medication. The difference between the groups is highly significant $\left(\chi^{2}=12.42, p<.001\right)$, and the effect size $p h i$ is robust ( $p h i=.53$ ).

\section{BORDERLINE PERSONALITY DISORDER SYMPTOMATOLOGY}

The mean number of BPD symptoms reported by the BPD-H group (5.91, $S D=1.85)$ was higher than that reported by the BPD-C group $(5.00, S D=$ 1.17), though the difference is only marginally significant, $t(43)=1.96, p=$ .058). Profile analysis (Harris, 1985) was conducted to determine whether the two BPD groups differ not only in severity of BPD symptoms, but also in type of symptoms displayed. ${ }^{2}$ Interestingly, the groups differed quite substantially on the test of shape in the profile analysis $(F(8,34)=4.88$, $p<.001$, eta $=.73$ ). This indicates that the groups showed a very different profile of borderline symptoms. Figure 1 displays the profile of symptoms, and Table 2 contains the data and comparison statistics.

These data suggest that although the BPD-H group displayed more BPD symptoms than the community BPD group, it is perhaps more interesting that they displayed somewhat different symptoms. Univariate chi-square analyses (Table 2) indicated that BPD-H participants showed significantly more self-harm and suicidality, emptiness, and a trend toward more dissociative experiences. Community participants showed a trend toward having more unstable interpersonal relationships. It seems logical that parasuicidal behavior and emptiness (which can lead to self-destructive behavior, (Shearer, 1994)) would distinguish these groups, given that hos-

2. Profile analysis yields three tests of the differences between the profiles: level determines whether one group is higher than the other overall (i.e., collapsed across groups), flatness indicates whether all symptoms are endorsed equally (collapsed across group), and shape indicates whether the two groups endorse different symptoms at different rates. When the shape analysis is significant (as in this case), it supercedes the other two analyses, just as an interaction does for main effects in an ANOVA. Therefore in the interest of space, we report only the results from the shape analysis. 


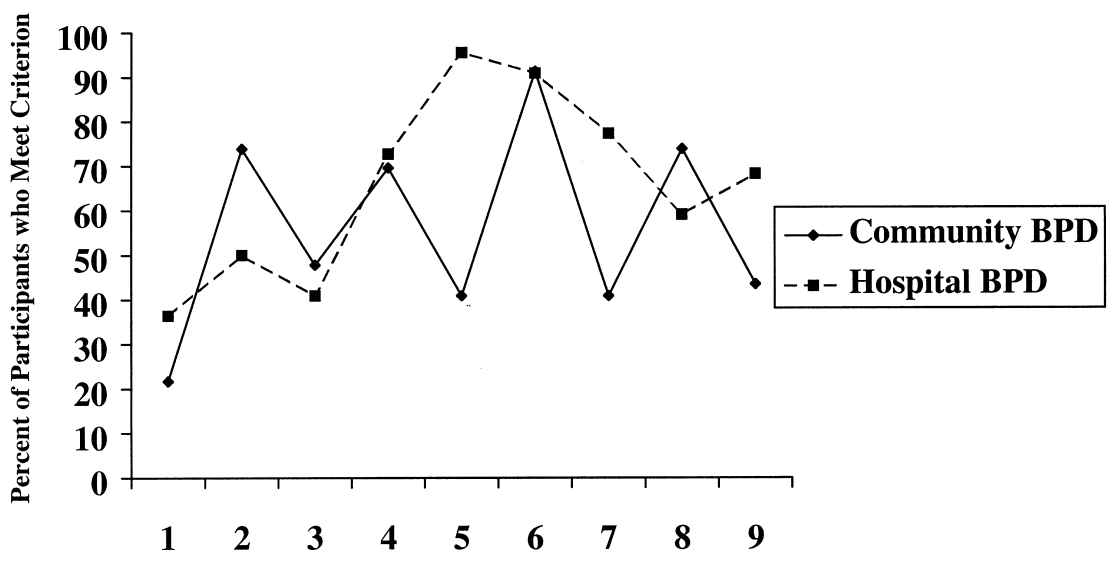

FIGURE 1. Profiles of BPD symptoms by group.

Note. 1 = Abandonment, 2 = Unstable Interpersonal Relations, 3 = Identity Disturbance, $4=$ Impulsivity, 5 = Self Mutilation/Suicide, $6=$ Affective Instability, $7=$ Emptiness, $8=$ Anger, $9=$ Dissociation

pitalization tends to be more likely to occur in individuals who harm themselves.

\section{AXIS I CHARACTERISTICS}

Axis I psychopathology in this sample was assessed using the SCID-NP. The number and percentage of subjects who met lifetime DSM-III-R Axis I diagnoses are presented in Table 3. Comparisons were conducted to determine whether there were differences in rates of Axis I disorders between the two BPD groups.

Results from the SCID interview indicate that, consistent with reports from other samples (Zanarini et al., 1998; Zimmerman, Rothschild, \& Chelminski, 2005; Lenzenweger, Lane, Loranger, \& Kessler, 2007), BPD

TABLE 2. Symptoms of Borderline Personality Disorder in the Hospital and Community Samples

\begin{tabular}{lccccc}
\hline \multicolumn{1}{c}{$\begin{array}{c}\text { Hospital } \\
\text { BPD } \\
\text { BPD Symptom }\end{array}$} & $\begin{array}{c}\text { Community } \\
\mathbf{B P D}\end{array}$ & & & \\
\hline Abandonment & $8(36.4)$ & $5(21.7)$ & 1.17 & .279 & .16 \\
Unstable Interpersonal Relations & $11(50.0)$ & $17(73.9)$ & 2.74 & .098 & .25 \\
Identity Disturbance & $9(40.9)$ & $11(47.8)$ & 0.22 & .641 & .07 \\
Impulsivity & $16(72.7)$ & $16(69.6)$ & 0.05 & .815 & .03 \\
Self-Mutilation & $21(95.5)$ & $9(40.9)$ & 15.09 & $<.001$ & .59 \\
Affective Instability & $20(90.9)$ & $21(91.3)$ & 0.00 & .963 & .00 \\
Emptiness & $17(77.3)$ & $9(40.9)$ & 6.02 & .014 & .37 \\
Anger & $13(59.1)$ & $17(73.9)$ & 1.11 & .292 & .16 \\
Dissociation & $15(68.2)$ & $10(43.5)$ & 2.78 & .096 & .25 \\
\hline Note. Numbers in parentheses are percentages. Phi is an effect size estimate for chi \\
square analyses (Rosenthal \& Rosnow, 1991)
\end{tabular}


TABLE 3. Lifetime DSM-III-R Axis I Diagnoses (Definite and Subthreshold) by Group

\begin{tabular}{|c|c|c|c|c|c|}
\hline Disorder & $\begin{array}{c}\text { Hospital } \\
\text { BPD } \\
(n=22) \\
\end{array}$ & $\begin{array}{c}\text { Community } \\
\text { BPD } \\
(n=23) \\
\end{array}$ & $\chi^{2}$ & $\underline{p}$ & phi \\
\hline Bipolar Disorder & $3(13.6)$ & $1 \quad(4.3)$ & 1.20 & .274 & .16 \\
\hline Bipolar NOS & $2(9.1)$ & $4(17.4)$ & 0.67 & .413 & .12 \\
\hline Major Depression & 17 (77.3) & $14(60.9)$ & 1.41 & .235 & .18 \\
\hline Dysthymia & $6(27.3)$ & $6(26.1)$ & 0.01 & .928 & .01 \\
\hline Alcohol Abuse & $2(9.1)$ & $2(8.7)$ & 0.00 & .963 & .00 \\
\hline Alcohol Dependence & $9(40.9)$ & $4(17.4)$ & 3.03 & .082 & .26 \\
\hline Other Substance Abuse/Dependence & $12(54.5)$ & $7(30.4)$ & 2.68 & .102 & .24 \\
\hline Panic Disorder & $8(36.4)$ & $7(30.4)$ & 0.18 & .673 & .06 \\
\hline Social Phobia & $3(13.6)$ & $3(13.0)$ & 0.00 & .953 & .00 \\
\hline Simple Phobia & $8(36.4)$ & $4(17.4)$ & 2.07 & .150 & .21 \\
\hline Obsessive-Compulsive Disorder & $3(13.6)$ & 4 (17.4) & 0.12 & .728 & .05 \\
\hline Generalized Anxiety Disorder & $1 \quad(4.5)$ & $2(8.7)$ & 0.31 & .577 & .08 \\
\hline Anorexia & 9 (4.09) & $2 \quad(8.7)$ & 6.32 & .012 & .37 \\
\hline Bulimia & 7 (31.8) & 3 (13.0) & 2.29 & .130 & .23 \\
\hline
\end{tabular}

Note. Numbers in parentheses are percentages.

${ }^{a}$ Due to the selection of controls for absence of psychopathology, only the data for the two BPD groups are reported here.

participants in both groups displayed a substantial amount of Axis I pathology. As might be expected (Gunderson \& Phillips, 1991), major depression was the disorder most prevalent in both BPD groups. This was followed by nonalcohol substance abuse in the BPD-H group, and followed by substance abuse and panic in the BPD-C group. Overall, there was a significantly greater amount of Axis I psychopathology in the BPD-H group relative to the $\mathrm{BPD}-\mathrm{C}$ group, (mean number of comorbid diagnoses $=4.00$, $\mathrm{SD}=1.77$ for BPD-H participants, and $M=2.57, \mathrm{SD}=1.75$ for BPD-C participants; $t(43)=2.73, p=.009$ ). Interestingly, though, with a Bonferroni correction for multiple comparisons setting the $p$ value for significance at .004 , the groups did not differ significantly on presence of any single Axis I condition.

\section{OTHER CLINICAL CHARACTERISTICS}

Table 4 displays general clinical characteristics of the three groups for the self-reported mood and personality variables. Not surprisingly, participants from both BPD groups reported more psychopathology and more maladaptive personality traits than did the control group participants. Omnibus $F$ tests comparing the three groups revealed that controls differed significantly from both groups of BPD subjects across all the mood and personality variables (all $F$ 's $<.001$ ). Contrast analyses (Rosenthal \& Rosnow, 1991; Rosenthal, Rosnow, \& Rubin, 2000) were then conducted to compare the two BPD groups, holding aside the control group (i.e., contrast weights of $-1,+1,0)$. As indicated in Table 4 , the BPD-H participants were more depressed at the time of testing (as assessed by the BDI) than were the BPD-C participants. However, BPD-H participants did not show elevated levels of trait-like vulnerability towards depression as assessed 
TABLE 4. Clinical Characteristics for the Hospital Borderline, Community Borderline, and Control Groups

\begin{tabular}{|c|c|c|c|c|c|c|}
\hline Characteristic & $\begin{array}{c}\text { Hospital } \\
\text { Borderline }\end{array}$ & $\begin{array}{c}\text { Community } \\
\text { Borderline }\end{array}$ & Control & $t^{\mathrm{a}}$ & $\boldsymbol{p}^{*}$ & $r$ \\
\hline GBI Depression & $\begin{array}{c}24.45 \\
(11.52)\end{array}$ & $\begin{array}{c}24.36 \\
(9.94)\end{array}$ & $\begin{array}{c}.95 \\
(1.68)\end{array}$ & 0.03 & .974 & .00 \\
\hline State Anxiety & $\begin{array}{c}48.91 \\
(15.07)\end{array}$ & $\begin{array}{c}47.48 \\
(10.78)\end{array}$ & $\begin{array}{c}26.45 \\
(5.29)\end{array}$ & 0.43 & .671 & .07 \\
\hline BDI Depression & $\begin{array}{c}19.18 \\
(13.04)\end{array}$ & $\begin{array}{l}13.48 \\
(9.09)\end{array}$ & $\begin{array}{l}1.20 \\
(1.70)\end{array}$ & 2.04 & .046 & .30 \\
\hline Dissociative Experiences Scale & $\begin{array}{c}26.47 \\
(15.46)\end{array}$ & $\begin{array}{c}23.70 \\
(13.62)\end{array}$ & $\begin{array}{l}8.15 \\
(8.15)\end{array}$ & 0.72 & .475 & .11 \\
\hline Buss-Durkee Assault & $\begin{array}{c}3.27 \\
(2.87)\end{array}$ & $\begin{array}{c}4.43 \\
(2.79)\end{array}$ & $\begin{array}{l}1.65 \\
(1.76)\end{array}$ & 1.53 & .131 & .23 \\
\hline Buss-Durkee Irritability & $\begin{array}{l}6.91 \\
(2.67)\end{array}$ & $\begin{array}{c}8.95 \\
(1.87)\end{array}$ & $\begin{array}{l}4.00 \\
(2.92)\end{array}$ & 2.74 & .008 & .39 \\
\hline Positive Affectivity (PANAS) & $\begin{array}{c}28.76 \\
(6.71)\end{array}$ & $\begin{array}{c}29.43 \\
(7.90)\end{array}$ & $\begin{array}{c}39.40 \\
(4.87)\end{array}$ & 0.33 & .740 & .05 \\
\hline Negative Affectivity (PANAS) & $\begin{array}{l}31.76 \\
(8.43)\end{array}$ & $\begin{array}{c}28.83 \\
(8.27)\end{array}$ & $\begin{array}{l}13.35 \\
(2.96)\end{array}$ & 1.37 & .177 & .21 \\
\hline
\end{tabular}

Note. Abbreviations are as follows: IPDE = International Personality Disorder Examination, $\mathrm{GBI}=$ General Behavior Inventory, BDI $=$ Beck Depression Inventory.

${ }^{\mathrm{a}}$ For each variable, the omnibus $F$ resulting from a one-way ANOVA across the three groups is highly significant (all $F \mathrm{~s}<.001$ ). In each case, this was due to the large differences between the control group and the two BPD groups. The $t$ tests reported in the table are from contrast analyses testing whether the two BPD groups differ from each other, holding aside the control group (i.e., contrast weights of $-1,+1,0$ ).

${ }^{*} p$ values are based on two-tailed tests of significance.

by the GBI. Interestingly, the BPD-C subjects reported more irritability (as measured by the Buss-Durkee) than did the BPD-H subjects. On most of the indicators, however, the two BPD groups did not differ significantly. This was an unexpected finding given that we had predicted more general impairment in the hospital group.

\section{DISCUSSION}

This study sought to determine whether persons with BPD could be readily ascertained from a nonclinical community population, and whether such individuals differed demographically and clinically from those ascertained from a clinical setting. Our strategy of advertising for personality traits associated with BPD yielded a community sample of individuals who indeed met DSM-IV criteria for BPD. Other investigators have found individuals with borderline traits in nonclinical populations (e.g., Trull, Useda, Conforti, \& Doan, 1997), though the participants in previous studies were ascertained by screening large unselected samples. Thus, although these studies did discover that individuals with BPD traits could be found in the community, the current study determined that individuals with BPD could be ascertained by specifically seeking out such traits. Using our approach, the number of individuals needed for screening is substantially diminished due to participants self-selecting for borderline traits. One limitation of this strategy is that potential study participants need to be able to recog- 
nize these traits in themselves. Additionally, as is to be expected, the nature of the material included on the advertisement could have affected the self-selection process, which is a limitation in nearly all volunteer subject recruitment schemes.

One of the two primary themes of our results concerns the existence of some important differences across hospitalized versus community BPD samples. The hospitalized and community BPD samples differed on some clinical and demographic dimensions, and yet were quite similar on others. The hospitalized group reported a greater number of BPD symptoms and displayed a different pattern of symptoms than did the community group. Not only did BPD-H participants engage in more self-harm and suicidal behavior, but they also experienced more feelings of emptiness than did the BPD-C participants. In addition, the BPD-H group had a lower IQ (although they were still in the average range), more hospitalizations, and more medication than the BPD-C group. The participants in the BPD-H group had a greater number of comorbid Axis I conditions relative to the BPD-C group, however, the groups did not differ on the presence of any one particular Axis I disorder. On all other clinical measures, the two groups did not differ. That is, they showed equal levels of trait depression, state and trait anxiety, dissociative experiences, and positive and negative affect. The research literature that describes clinical setting versus community-based BPD subjects remains remarkably modest, thus there is little to compare our results with in terms of contemporary studies. An implication of our results, therefore, is the need for additional comparisons of clinical BPD populations with both outpatient as well as community-based BPD populations.

The second primary theme of our study concerns our methodology for the detection of community-based BPD pathology. These findings suggest that individuals with diagnosable BPD can indeed be ascertained from a community population through the use of advertisements. This is particularly salient as the population prevalence of BPD is 1.4\% (Lenzenweger et al., 2007), which suggests a nontrivial rate of this disorder in the community at large and one well worth more intensive study. In addition, there may be advantages to selecting study participants from one population relative to the other, depending upon the research question at hand. For example, if an investigator is seeking unmedicated BPD participants for a research protocol (e.g., neuroimaging study), a community screening approach might be particularly helpful. Alternatively, if an investigator is studying self-harm or suicidal behavior in BPD, clinical samples might yield more eligible participants. Treatment studies that seek to recruit their subjects from the community rather than from clinical settings might also take advantage of this approach for sample assembly. Given that there are individuals with BPD in the community who never appear in clinical settings (cf., Lenzenweger et al., 2007), these data suggest a useful way of locating them that seems reasonably cost efficient, reliable, and valid. The data also suggest that although these individuals show a some- 
what distinct pattern of symptoms and lower levels of Axis I comorbidity than those from a clinical setting, the two groups are, in many ways, more similar than different. Finally, as regards clinical implications, our results suggest that the hospitalized BPD patients may require a greater therapeutic focus on issues related to self-harm, emptiness, and dissociation, whereas BPD individuals in the community might require a greater therapeutic focus on interpersonal dysfunction.

\section{REFERENCES}

American Psychiatric Association. (1994). Diagnostic and statistical manual of mental disorders (4th ed.). Washington, DC: Author.

Beck, A. T., Ward, C. H., Mendelsohn, M., Mock, J. E., \& Erbaugh, J. K. (1961). An inventory for measuring depression. Archives of General Psychiatry, 4, 561-571.

Bernstein, E. M., \& Putnam, F. W. (1986). Development, reliability, and validity of a dissociation scale. Journal of Nervous and Mental Disease, 174, 727-734.

Brown, G. L., Goodwin, F. K., Ballenger, J. C., Goyer, P. F., \& Major, L. F. (1979). Aggression in humans correlates with cerebrospinal fluid amine metabolites. Psychiatry Research, 1, 131-139.

Buss, A. H., \& Durkee, A. (1957). An inventory for assessing different kinds of hostility. Journal of Consulting Psychology, 21, 343-349.

Carlson, E. B., \& Putnam, F. W. (1993). An update on the dissociative experiences scale. Dissociation, 6, 16-27.

Clark, L. A., Watson, D., \& Reynolds, S. (1995). Diagnosis and classification of psychopathology: Challenges to the current system and future directions. Annual Review of Psychology, 46, $121-$ 153.

Clifton, A., Pilkonis, P. A., \& McCarty, C. (2007). Social networks in borderline personality disorder. Journal of Personality Disorders, 21, 434-441.

Coccaro, E. F., Siever, L. J., Klar, H. M., Maurer, G., Cochrane, K., Cooper, T. B., Mohs, R. C., \& Davis, K. L. (1989). Serotonergic studies in patients with affective and personality disorder: Correlates with suicidal and impulsive aggressive behavior. Archives of General Psychiatry, 46, 587-599.
Depue, R. A., Kraus, S., Spoont, M. R., \& Arbisi, P. (1989). General behavior inventory identification of unipolar and bipolar affective conditions in a nonclinical university population. Journal of Abnormal Psychology, 98, 117-126.

Depue, R. A., \& Lenzenweger, M. F. (2005). A neurobehavioral model of personality disturbance. In M. F. Lenzenweger \& J. F. Clarkin (Eds.), Major theories of personality disorder (2nd ed) (pp. 391453). New York: Guilford.

Gottesman, I. I., \& Gould, T. D. (2003). The endophenotype concept in psychiatry: Etymology and strategic intentions. American Journal of Psychiatry, 160, 636-645.

Gunderson, J. G., \& Phillips, K. A. (1991). A current view on the interface between borderline personality disorder and depression. American Journal of Psychiatry, 148, 967-975.

Harris, R. J. (1985). A primer of multivariate statistics. (2nd ed.). New York: Academic Press.

Hurt, S. W., Clarkin, J. F., Frances, A., Abrams, R., \& Hunt, H. (1985). Discriminant validity of the MMPI for borderline personality disorder. Journal of Personality Assessment, 49, 56-61.

Koenigsberg, H. (1982). A comparison of hospitalized and nonhospitalized borderline patients. American Journal of Psychiatry, 139, 1292-1297.

Korfine, L. (1998). Memory functioning in borderline personality disorder. Unpublished doctoral dissertation, Harvard University, Cambridge.

Korfine, L., \& Hooley, J. M. (2000). Directed forgetting of emotional stimuli in borderline personality disorder. Journal of Abnormal Psychology, 109, 214-221.

Lenzenweger, M. F., Lane, M., Loranger, A. W., \& Kessler, R. C. (2007). DSM-IV 
personality disorders in the national comorbidity survey replication (NCSR). Biological Psychiatry, 62, 553-564. Lenzenweger, M. F., Loranger, A. W., Korfine, L., \& Neff, C. (1997). Detecting personality disorders in a nonclinical population: Application of a 2-stage procedure for case identification. Archives of General Psychiatry, 54, 345-351.

Loranger, A. W. (1994). Omnibus personality inventory manual. New York Hospital-Cornell Medical Center, Westchester Division. White Plains, New York.

Loranger, A. W. (1999). The international personality disorder examination (IPDE) DSM-IV and $I C D-10$ modules. Odessa, FL: Psychological Assessment Resources.

Loranger, A. W. (2002). OMNI personality inventory and OMNI-IV personality disorder inventory manual. Odessa, FL: Psychological Assessment Resources.

Loranger, A. W., Sartorius, N., Andreoli, A., Berger, P., Channabasavanna, S. M., Coid, B., et al. (1994). The international personality disorder examination (IPDE): The World Health Organization/alcohol, drug abuse, and mental health administration international pilot study of personality disorders. Archives of General Psychiatry, 51, 215224.

Maher, B. A. (2003). Psychopathology and delusions: Reflections on methods and models. In Lenzenweger, M. F., \& Hooley, J. M. (Eds), Principles of experimental psychopathology: Essays in honor of Brendan A. Maher (pp. 9-28). Washington, DC: American Psychological Association.

Rosenthal, R., \& Rosnow, R. L. (1991). Essentials of behavioral research: Methods and data analysis (2nd Edition). New York: McGraw-Hill.

Rosenthal, R., Rosnow, R. L., \& Rubin, D. B. (2000). Contrasts and effect sizes in behavioral research: A correlational ap- proach. New York: Cambridge University Press.

Shearer, S. (1994). Phenomenology of selfinjury among inpatient women with borderline personality disorder. Journal of Nervous and Mental Disease, $182,524-526$.

Spielberger, C. D. (1983). Manual for the state-trait anxiety inventory. Palo Alto, CA: Consulting Psychologists Press.

Spitzer, R. L., Williams, J.B.W., Gibbon, M., \& First, M. B. (1990). User's guide for the structured clinical interview for $D S M-I I I-R$. Washington, DC: American Psychiatric Press.

Trull, T. J., Useda, D., Conforti, K., \& Doan, B. (1997). Borderline personality disorder in nonclinical young adults: 2 . Two-year outcome. Journal of Abnormal Psychology, 106, 307-314.

Watson, D., Clark, L. A., \& Tellegen, A. (1988). Development and validation of brief measures of positive and negative affect: The PANAS scales. Journal of Personality and Social Psychology, 54, 1063-1070.

Widiger, T. A., \& Frances, A. (1985). The DSM-III personality disorders: Perspectives from psychology. Archives of General Psychiatry, 42, 615-623.

Widom, C. S. (1977). A methodology for studying noninstitutionalized psychopaths. Journal of Consulting and Clinical Psychology, 45, 674-683.

Zachary, (1991). Shipley institute of living scale (Rev. ed.). Los Angeles, CA: Western Psychological Services.

Zanarini, M. C., Frankenburg, F. R., Dubo, E. D., Sickel, A. E., Trikha, A., Levin, A., \& Reynolds, V. (1998). Axis I comorbidity of borderline personality disorder. American Journal of Psychiatry, 155, 1733-1739.

Zimmerman, M., Rothschild, L., \& Chelminski, I. (2005). The prevalence of DSMIV personality disorders in psychiatric outpatients. American Journal of Psychiatry, 162, 1911-1918. 